\title{
Contemporary short- and mid-term outcomes of transcatheter aortic valve replacement for nonagenarians in Japan
}

\author{
Hiroshi Kurazumi ${ }^{1}$, Akihito Mikamo ${ }^{1}$, Ryo Suzuki ${ }^{1}$, Bungo Shirasawa ${ }^{1}$, Yosuke Miyazaki ${ }^{1}$, \\ Hiroki Tateishi ${ }^{1}$, Tetsuro Oda ${ }^{1}$, Takayuki Okamura ${ }^{1}$, Masafumi Yano ${ }^{1}$, and Kimikazu \\ Hamano $^{1}$ \\ ${ }^{1}$ Yamaguchi University School of Medicine Graduate School of Medicine
}

September 16, 2020

\begin{abstract}
Objectives: The large-scale adoption of transcatheter aortic valve implantation (TAVI) and aging of the population in Japan have led to an increase in the number of TAVI procedures among elderly patients. However, the clinical outcomes of TAVI for nonagenarians in Japan are unclear. The aim of this study was to clarify the outcomes of TAVI in nonagenarians with severe aortic stenosis in a real-world Japanese setting. Methods: This study retrospectively assessed the early and mid-term clinical outcomes after TAVI in nonagenarians (group $\mathrm{N} ; \mathrm{n}=23$ ) in comparison to those of younger patients (group Y; $\mathrm{n}=117$ ). Results: There were no postoperative deaths in either group. Although patients in group N required longer hospital stays (19 \pm 32.1 days vs. $12.1 \pm 9.3$ days, $\mathrm{p}=0.04$ ), all other early outcomes were equivalent in the two groups. The overall survival at 5 years tended to be lower in group $\mathrm{N}$ but the difference was not statistically significant $(29.5 \%$ vs. $51.1 \%, \mathrm{p}=0.26)$. The freedom from cardiac events at 5 years rate was equivalent in both groups $(69.5 \%$ vs. $66.0 \%, \mathrm{p}=0.68)$. There were no late cardiac deaths in group $\mathrm{N}$. The freedom from late cardiac death rate at 5 years was $100 \%$ in group $\mathrm{N}$ and $84.6 \%$ in group Y. Conclusions: The early and mid-term clinical outcomes of TAVI in nonagenarians were comparable to those in younger patients. These results indicate that TAVI is effective for aortic stenosis in Japanese nonagenarians and may help prevent cardiac deaths.
\end{abstract}

\section{INTRODUCTION}

According to the 2008 World Health Organization report, Japan is the country with the longest life expectancy. ${ }^{1}$ The latest report from the Japanese Ministry of Health, Labor and Welfare stated that the life expectancy has reached 81.2 years in men and 87.3 years in women, with 438,000 people over 90 years of age. ${ }^{2}$ Unfortunately, this extreme-aged group has an increased prevalence of aortic stenosis and is more likely to have co-morbid conditions, which poses a dilemma to cardiologists and cardiac surgeons when having to choose between conservative or interventional treatment.

Seven years ago, surgical aortic valve replacement (SAVR) was the only treatment for the clinical management of severe aortic stenosis in Japan. However, since 2013, transcatheter aortic valve implantation (TAVI) has been covered by Japanese national health insurance, making it a less invasive alternative to SAVR. ${ }^{3,4}$ TAVI was subsequently rapidly adopted, as previously seen in Europeans countries. ${ }^{5}$

The widespread use of TAVI and the aging of the population in Japan have led to an increase in the number of TAVI procedures in elderly patients. Some Western studies have reported the outcomes of TAVI for nonagenarians. ${ }^{6-8}$ However, there are few reports on TAVI for nonagenarians from Asian countries. The aim of this study was to clarify the outcomes of TAVI in nonagenarians with severe aortic stenosis in Japan.

\section{MATERIALS AND METHODS}


This study was approved by the Institutional Review Board of Yamaguchi University Hospital (Study ID: H2019-071) with an opt-out consent process, and was conducted in accordance with the Declaration of Helsinki.

A total of 140 patients who were treated at our institution for severe aortic stenosis from April 2014 to July 2019 were included in the study. All patients were assessed by a multidisciplinary cardiac team that included cardiac surgeons, cardiologists, cardiac anesthesiologist, and physical therapists to determine the appropriate treatment strategy. We retrospectively assessed the early and mid-term clinical outcomes after TAVI in nonagenarians (group $\mathrm{N} ; \mathrm{n}=23$ ) in comparison to those of younger patients (group $\mathrm{Y} ; \mathrm{n}=117$ ).

\subsection{Operative procedure}

TAVI was performed under general anesthesia with endotracheal intubation. A temporary right ventricle pacing lead wire was inserted though the right jugular vein and used when needed. The approach to deployment of the transcatheter prosthetic valve was discussed by the cardiac team. The trans-femoral approach was considered as the initial choice. If a femoral approach was not feasible, a different approach was utilized. The type and size of the prosthetic valves used were determined according to the findings in the aortic valve complex on preoperative enhanced cardiac computed tomography. The Edwards Sapien XT and Sapien 3 (Edwards Lifesciences, Irvine, CA) were used as balloon-expandable valves. The Core Valve, Evolut R, and Evolut PRO (Medtronic Inc., Minneapolis, MN) were used as self-expandable valves.

\subsection{Statistical analysis}

Continuous data are expressed as the mean \pm standard deviation and their differences were evaluated using Student's $t$-test. For categorical data, the differences were evaluated using the $\chi^{2}$ and Fisher exact tests. Time-to-event analyses were performed using Kaplan-Meier estimates and compared between groups using the log-rank test. Independent predictors of overall survival were determined using Cox regression analysis. The multivariable models included covariates with a $\mathrm{p}<0.10$ in the univariate analyses. All statistical analyses were performed using StatView version 5.0 software (SAS Institute, Cary, NC). In each analysis, p $<0.05$ was regarded as significant.

\section{RESULTS}

\subsection{Patient characteristics}

Baseline patient characteristics are shown in Table 1. The mean age was $83.2 \pm 4.7$ years in group Y and $92.1 \pm 1.9$ years in group $\mathrm{N}(\mathrm{p}<0.0001)$. Preoperative pacemaker implantation was slightly higher in group $\mathrm{N}$ than in group Y (17.3\% vs. $5.9 \%)$. The other patient characteristics did not differ significantly between the two groups. The Society of Thoracic Surgery (STS) risk score was $7.7 \%$ in group Y and $8.4 \%$ in group N.

\subsection{Operative parameters}

Operative procedures and intraoperative findings are shown in Table 2. In this study, $75 \%$ of patients underwent TAVI through the trans-femoral approach, $19 \%$ through the trans-apical, $3 \%$, through the transsubclavian, and $2 \%$ through the ascending aorta. A balloon-expandable valve was implanted in $72 \%$ of patients, while a self-expandable valve was implanted in $28 \%$. The interventional approach, type of prosthetic valve, procedure time, and blood transfusion rates were statistically equivalent between the two groups.

\subsection{Early outcomes}

No inpatient deaths occurred in both the groups. The hospital stay was significantly longer in group $\mathrm{N}$ than in group Y (19 \pm 32.1 days vs. $12.1 \pm 9.3$ days, $\mathrm{p}=0.04)$. However, the incidence of any complication, including the need for pacemaker implantation, paravalvular leakage, cerebral infarction, and acute type B dissection, was equivalent in the two groups (Table 3 ).

We assessed postoperative cardiac function using transthoracic echocardiography (Supplemental Figure 1). The aortic valve area was significantly increased in both groups. Peak systolic velocity and mean pressure gra- 
dient were significantly decreased in both groups. There were no significant differences in echocardiographic findings between the two groups.

\subsection{Mid-term outcomes}

The overall 5-year survival rate was $35.1 \%$ across the entire cohort; $51.1 \%$ in group $\mathrm{N}$, and $29.5 \%$ in group $\mathrm{Y}$ (log-rank test, group N vs. group $\mathrm{Y}, \mathrm{p}=0.26$; Figure $1 \mathrm{~A})$. The 5 -year freedom from cardiac events rate was $66.7 \%$ across the entire cohort; $69.5 \%$ in group $\mathrm{N}$, and $66.0 \%$ in group $\mathrm{Y}$ (log-rank test, group $\mathrm{N}$ vs. group $\mathrm{Y}, \mathrm{p}=0.68$; Figure 1B). In terms of 5 -year freedom from cardiac death, the rate was $88.7 \%$ across the entire cohort; $100 \%$ in group N, and $84.6 \%$ in group Y (Figure 1C).

In total, 36 remote deaths occurred across the entire cohort, with 7 in group $\mathrm{N}$ and 29 in group $\mathrm{Y}$. The causes of remote death in group $\mathrm{N}$ were pneumonia in 3 patients, other infectious disease in 3 , and malignancy in 1 , with no cardiac deaths. On the other hand, the major causes in group Y were cardiac death in 8 patients, pneumonia in 8 , cerebrovascular disease in 3 , malignancy in 2 , and other causes in 8 .

\subsection{Predictors of mortality after TAVI}

We used Cox proportional hazard models to analyze the predictors of mortality after TAVI, as shown in Table 4 . The univariate analysis revealed that preoperative serum albumin and hemoglobin were associated with mortality. In the multivariate analysis, only preoperative serum albumin showed a tendency towards predicting mortality, however the association did not reach statistical significance (hazard ratio: 0.54, 95\% confidence interval CI: $0.65-1.03, \mathrm{p}=0.08)$.

\section{DISCUSSION}

Life expectancy varies from country to country and in addition, the healthcare systems of each country are unique in themselves. In Japan, where health insurance is a requirement, the healthcare delivery environment is different as compared to other countries where health insurance is not a requirement. There are several reports on the outcomes of TAVI for nonagenarians in Western countries. ${ }^{6-8}$ However, to our knowledge, this is the first report to investigate outcomes in the Japanese population. Takeji et al. reported that the current hospital mortality rate of TAVI in Japan is $1.3 \%$, suggesting that it has a high success rate and is being performed safely with very low mortality. ${ }^{3}$ This study revealed that TAVI in nonagenarians have excellent early- and mid-term outcomes. The in-hospital mortality rate of our nonagenarian cohort was $0 \%$, which was statistically equivalent to the younger patients' cohort (0\%). Although hospital stays were longer in the nonagenarian cohort, the other early outcomes were comparable, indicating that TAVI can be safely performed even in very elderly populations. Investigators from Western countries have shown that TAVI in nonagenarians can achieve acceptable in-hospital outcomes and that age alone should not exclude patients from treatment, ${ }^{6-8}$ a viewpoint that is supported by our findings.

A decade ago, SAVR was the only effective therapy for aortic valve stenosis. The development of TAVI has dramatically changed the surgical treatment of aortic valve stenosis. Previous studies with nonagenarian cohorts showed that early mortality after SAVR ranged from $11 \%$ to $17 \% .^{9,10}$ In contrast, the in-hospital or 30 -day mortality rates after TAVI in nonagenarians has been reported as $0 \%-8.7 \%$ in recent observational studies, showing a distinct advantage. ${ }^{6,7}$ In fact, there were no in-hospital or 30-day mortalities in our nonagenarian cohort. Although the long-term results of TAVI remain unclear, it is a useful therapeutic option and a reasonable alternative to SAVR in nonagenarians based on their relatively short life expectancy.

Our results showed that nonagenarian patients required longer hospital stays. Prolonged hospitalization can cause postoperative muscle weakness and deterioration of activities of daily living (ADL). Stehli et al. reported that deterioration of ADL after TAVI is more frequent in older patients and that $25 \%$ of nonagenarians transition to aged-care facilities within 1 year after TAVI. ${ }^{7}$ We believe that this points to a particular disadvantage of TAVI in very elderly patients. In this cohort, only 15 of 23 nonagenarians had frailty assessment data available as these assessments were not routinely performed during the early period of our series. Although the sample size is limited, we could not find any deterioration in frailty status in the early phase after TAVI (Supplemental table1). However, the data is insufficient for assessing the possible 
future changes in ADL and quality of life. Unconscious scaling back of physical activity in patients with cardiac disease is a well-characterized phenomenon. Gradual improvement in activity may be possible after recovery of cardiac function (Supplemental Figure1). Further investigations into long-term ADL outcomes are required.

The freedom from cardiac events rates in each group were almost equivalent in this study. Interestingly no late cardiac deaths occurred in the nonagenarian cohort. The Japanese Ministry of Health, Labor and Welfare reported that the top 5 causes of mortality in nonagenarians are cardiac disease, pneumonia, senility, cerebrovascular disease, and malignancy. ${ }^{11}$ In our nonagenarian cohort, the causes of late mortality were pneumonia in 3 patients, other infectious disease in 3 , and malignancy in 1 , but there were no cardiac deaths. Thus, TAVI may contribute to the avoidance of cardiac death in nonagenarians.

The wide-spread adoption of TAVI and the aging of the population have led to an increase in the number of procedures performed worldwide. The identification of prognostic factors is thus essential for patient selection and stratification in the TAVI era. Various predictors of prognosis after TAVI have been reported; for example, anemia, intra- or post-operative blood transfusion, psoas muscle area, and appetite immediately before discharge were associated with postprocedural mortality. ${ }^{12-15}$ In this study, lower preoperative serum albumin seemed to be associated with poor long-term outcomes, but the results were not statistically significant $(\mathrm{p}=0.08)$. Serum albumin is a known frailty marker and may be a potential predictor of TAVI outcomes. In this study, age was not a predictor of prognosis despite generally being a significant factor in all procedures. Older patients have more co-morbidities and are at a higher operative risk. In fact, major operative risk scores, including the STS risk score, EuroSCORE, and JapanSCORE, identified older age as independent operative risk factor. ${ }^{16-18}$ We believe that our results could be explained by the equivalent risk scores in the nonagenarian and the younger age groups (Table 1). This indicates that the nonagenarian patients may have been selected to some degree and be in relatively better condition as compared to the younger group, which would affect the assessment of age as a prognostic indicator.

This study has several limitations. Since this was a retrospective, observational study, selection bias may be present. The sample size was limited because our hospital is not a high-volume center. Furthermore, data regarding outcomes of conservative medical therapy in nonagenarian aortic stenosis patients were not available.

\section{CONCLUSIONS}

The early and mid-term clinical outcomes of TAVI in selected nonagenarians were comparable to those in younger patients and TAVI may contribute to the prevention of cardiac death in nonagenarians. These findings indicate that TAVI may be an effective treatment for aortic stenosis, even in nonagenarian patients.

\section{Author Contributions}

Hiroshi Kurazumi: Data analysis, Drafting article,

Akihito Mikamo, Takayuki Okamura: Concept/design

Ryo Suzuki, Bungo Shirasawa, Yosuke Miyazaki, Hiroki Tateishi, Tetsuro Oda: Data collection

Masafumi Yano, Kimikazu Hamano: Approval of article

\section{Disclosure statement}

The authors declare no conflict of interest.

\section{References}

World Health Statistics 2018: Monitoring health for the SDGs [monograph on the Internet]. Geneva: World Health Organization; 2018 [Cited 26 Apr 2020]. Available from:

https://www.who.int/gho/publications/world_health_statistics/2018/en/ 
Director-General for Statistics and Information Policy. Abridged Life Tables For Japan 2018. Tokyo: Ministry of Health, Labour and Welfare; 2018 [Cited 26 Apr 2020]. Available from:

https://www.mhlw.go.jp/english/database/db-hw/lifetb18/index.html

1. Takeji Y, Taniguchi T, Morimoto T, et al. Transcatheter Aortic Valve Implantation vs. Surgical Aortic Valve Replacement for Severe Aortic Stenosis in Real-World Clinical Practice. Circ J 2020;84:806-814.

2. Leon MB, Smith CR, Mack M, et al. Transcatheter aortic-valve implantation for aortic stenosis in patients who cannot undergo surgery. N Engl J Med 2010;363:1597-1607.

3. Durko AP, Osnabrugge RL, Van Mieghem NM, et al. Annual number of candidates for transcatheter aortic valve implantation per country: current estimates and future projections.

Eur Heart J 2018;39:2635-2642.

1. Noble S, Frangos E, Samaras N, et al. Transcatheter aortic valve implantation in nonagenarians: effective and safe. Eur J Intern Med 2013;24:750-755.

2. Stehli J, Koh JQS, Duffy SJ, et al. Comparison of outcomes of transcatheter aortic valve implantation in patients aged $>90$ years versus $<90$ years. Am J Cardiol 2019;124:1085-1090.

3. Manolis AS, Manolis AA. Transcatheter aortic valve implantation in nonagenarians: selectively feasible or extravagantly futile? Ann Cardiothorac Surg 2017;6:524-531.

4. Roberts WC, Ko JM, Matter GJ. Aortic valve replacement for aortic stenosis in nonagenarians.

Am J Cardiol 2006;98:1251-1253.

Edwards MB, Taylor KM. Outcomes in nonagenarians after heart valve replacement operation.

Ann Thorac Surg 2003;75:830-834.

Director-General for Statistics and Information Policy. Mortality probability by cause of death. Tokyo: Ministry of Health, Labour and Welfare; 2018 [Cited 26 Apr 2020]. Available from:

https://www.mhlw.go.jp/english/database/db-hw/lifetb18/dl/lifetb18-04.pdf.

1. Rheude T, Pellegrini C, Michel J, et al. Prognostic impact of anemia and iron-deficiency anemia in a contemporary cohort of patients undergoing transcatheter aortic valve implantation. Int J Cardiol 2017;244:93-99.

2. Escárcega RO, Lipinski MJ, Magalhaes MA, et al. Impact of blood transfusions on short- and long-term mortality in patients who underwent transcatheter aortic valve implantation. Am J Cardiol 2015;115:9399.

3. Garg L, Agrawal S, Pew T, et al. Psoas Muscle Area as a Predictor of Outcomes in Transcatheter Aortic Valve Implantation. Am J Cardiol 2017;119:457-460.

4. Taniguchi Y, Sakakura K, Yuri K, et al. Appetite Predicts Clinical Outcomes in High Risk Patients Undergoing Trans-Femoral TAVI. Int Heart J 2019;60:1350-1357.

5. Kurazumi H, Mikamo A, Fukamitsu G, et al. Validation of the JapanSCORE versus the logistic EuroSCORE for predicting operative mortality of cardiovascular surgery in Yamaguchi University Hospital. Gen Thorac Cardiovasc Surg 2011;59:599-604.

6. Nashef SA, Roques F, Sharples LD, et al. EuroSCORE II. Eur J Cardiothorac Surg 2012;41:734-744.

7. Shroyer AL, Plomondon ME, Grover FL, Edwards FH. The 1996 coronary artery bypass risk model: the Society of Thoracic Surgeons Adult Cardiac National Database. Ann Thorac Surg 1999;67:1205-1208.

\section{Figure Legends}

\section{Figure 1. Mid-term outcomes}

(A) Cumulative survival, (B) freedom from cardiac events, (C) and freedom from cardiac death curves. The survival curve of the overall cohort is presented as a dashed black line, that of the nonagenarian group $(\mathrm{N})$ is presented as a solid black line, and that of the younger group $(\mathrm{Y})$ is presented as a solid gray line. 


\section{TABLES}

Table 1. Preoperative patients' characteristics

\begin{tabular}{|c|c|c|c|c|}
\hline & $\begin{array}{l}\text { Entire cohort } \\
(\mathrm{n}=140)\end{array}$ & $\mathrm{N}$ group $(\mathrm{n}=23)$ & $Y$ group $(n=117)$ & $\mathrm{p}$ value \\
\hline $\begin{array}{l}\text { Age (years) } \\
\text { [range] }\end{array}$ & $\begin{array}{l}84.6 \pm 5.4 \\
{[69-97]}\end{array}$ & $\begin{array}{l}92.1 \pm 1.9 \\
{[90-97]}\end{array}$ & $\begin{array}{l}83.2 \pm 4.7 \\
{[69-89]}\end{array}$ & $<0.0001$ \\
\hline Male & $47(33.5 \%)$ & $5(21.7 \%)$ & $42(35.8 \%)$ & 0.18 \\
\hline Hypertension & $126(90.0 \%)$ & $22(95.6 \%)$ & $104(88.8 \%)$ & 0.32 \\
\hline Dyslipidemia & $77(55 \%)$ & $12(52.1 \%)$ & $65(55.5 \%)$ & 0.76 \\
\hline $\mathrm{DM}$ & $38(27.1 \%)$ & $4(17.3 \%)$ & $34(29.0 \%)$ & 0.25 \\
\hline IHD & $55(39.2 \%)$ & $4(17.3 \%)$ & $51(43.5 \%)$ & 0.13 \\
\hline CVD & $36(25.7 \%)$ & $4(17.3 \%)$ & $32(27.3 \%)$ & 0.30 \\
\hline COPD & $6(4.2 \%)$ & 0 & $6(5.1 \%)$ & 0.58 \\
\hline Smoking & $9(6.4 \%)$ & 0 & $9(7.6 \%)$ & 0.35 \\
\hline Chronic AF & $21(15.0 \%)$ & $4(17.3 \%)$ & $17(14.5 \%)$ & 0.72 \\
\hline PMI & $11(7.8 \%)$ & $4(17.3 \%)$ & $7(5.9 \%)$ & 0.09 \\
\hline Malignancy & $7(5.0 \%)$ & $1(4.3 \%)$ & $6(5.1 \%)$ & 0.98 \\
\hline $\begin{array}{l}\text { Previous cardiac } \\
\text { surgery }\end{array}$ & $11(7.8 \%)$ & $1(4.3 \%)$ & $10(8.5 \%)$ & 0.49 \\
\hline $\begin{array}{l}\text { Serum creatinine } \\
(\mathrm{mg} / \mathrm{dl})\end{array}$ & $1.01 \pm 0.31$ & $0.98 \pm 0.29$ & $1.02 \pm 0.29$ & 0.60 \\
\hline $\begin{array}{l}\text { Serum albumin } \\
(\mathrm{g} / \mathrm{dl})\end{array}$ & $3.66 \pm 0.40$ & $3.74 \pm 0.38$ & $3.64 \pm 0.40$ & 0.27 \\
\hline $\begin{array}{l}\text { Hemoglobin } \\
(\mathrm{g} / \mathrm{dl})\end{array}$ & $10.80 \pm 1.68$ & $10.34 \pm 1.53$ & $10.89 \pm 1.70$ & 0.15 \\
\hline \multicolumn{5}{|l|}{ Oral } \\
\hline \multicolumn{5}{|l|}{ administration } \\
\hline $\mathrm{Ca}^{2+}$ blocker & $67(47.8 \%)$ & $13(56.5 \%)$ & $54(46.1 \%)$ & 0.36 \\
\hline ACE-I & $34(24.2 \%)$ & $5(21.7 \%)$ & $29(24.7 \%)$ & 0.75 \\
\hline $\mathrm{ARB}$ & $57(40.7 \%)$ & $13(56.5 \%)$ & $44(37.6 \%)$ & 0.09 \\
\hline Statins & $62(44.2 \%)$ & $10(43.4 \%)$ & $52(44.4 \%)$ & 0.93 \\
\hline \multicolumn{5}{|l|}{ Risk score } \\
\hline STS risk score & $7.9 \pm 4.6$ & $8.4 \pm 4.6$ & $7.7 \pm 4.8$ & 0.50 \\
\hline EuroSCORE II & $5.1 \pm 4.7$ & $5.4 \pm 3.3$ & $5.0 \pm 4.9$ & 0.72 \\
\hline JapanSCORE & $7.2 \pm 6.2$ & $5.1 \pm 4.7$ & $7.6 \pm 6.8$ & 0.09 \\
\hline
\end{tabular}

ACE-I: angiotensin converting enzyme inhibitor, AF: atrial fibrillation, ARB: angiotensin II receptor blocker, COPD: chronic obstructive pulmonary disease, CVD: cerebral vascular disease, DM: diabetes mellitus, IHD: ischemic heart disease, PMI: pace maker implantation, .

Table 2. Operative procedures and parameters

\begin{tabular}{lllll}
\hline & $\begin{array}{l}\text { Entire cohort } \\
(\mathrm{n}=140)\end{array}$ & $\mathrm{N}$ group $(\mathrm{n}=23)$ & Y group $(\mathrm{n}=117)$ & p value \\
\hline Approach & & & & \\
Femoral & $105(75.0 \%)$ & $17(73.9 \%)$ & $88(75.2 \%)$ & 1.00 \\
Apical & $27(19.3 \%)$ & $4(17.3 \%)$ & $23(19.7 \%)$ & 1.00 \\
Subclavian & $5(3.6 \%)$ & $1(4.4 \%)$ & $4(3.4 \%)$ & 1.00
\end{tabular}




\begin{tabular}{lllll}
\hline & $\begin{array}{l}\text { Entire cohort } \\
(\mathrm{n}=140)\end{array}$ & N group $(\mathrm{n}=23)$ & Y group $(\mathrm{n}=117)$ & p value \\
\hline $\begin{array}{l}\text { Aorta } \\
\text { Prosthetic valves }\end{array}$ & $3(2.1 \%)$ & $1(4.4 \%)$ & $2(1.7 \%)$ & 0.41 \\
$\begin{array}{l}\text { Balloon- } \\
\text { expandable }\end{array}$ & $101(72.2 \%)$ & $16(69.6 \%)$ & $85(72.6 \%)$ & \\
$\begin{array}{l}\text { Size }(\mathrm{mm}) \\
20 / 23 / 26 / 29\end{array}$ & $5 / 70 / 25 / 1$ & $3 / 12 / 1 / 0$ & $2 / 58 / 24 / 1$ & 0.80 \\
$\begin{array}{l}\text { Self-expandable } \\
\begin{array}{l}\text { Size }(\mathrm{mm}) \\
23 / 26 / 29\end{array}\end{array}$ & $39(27.8 \%)$ & $7(30.4 \%)$ & $32(27.4 \%)$ & [Balloon vs. \\
$\begin{array}{l}\text { Operation time } \\
\text { (min) }\end{array}$ & $149 \pm 40$ & $0 / 6 / 1$ & $2 / 17 / 13$ & Self-expandable] \\
Blood transfusion & $47(33.5 \%)$ & $159 \pm 40$ & $147 \pm 40$ & 0.20 \\
\hline
\end{tabular}

Table 3. Early clinical outcomes

\begin{tabular}{|c|c|c|c|c|}
\hline & $\begin{array}{l}\text { Entire cohort } \\
(\mathrm{n}=140)\end{array}$ & $N$ group $(n=23)$ & $Y$ group $(n=117)$ & $\mathrm{p}$ value \\
\hline In-hospital death & 0 & 0 & 0 & 1.00 \\
\hline ICU stay (days) & $1.9 \pm 1.1$ & $2.0 \pm 1.1$ & $1.9 \pm 1.1$ & 0.76 \\
\hline $\begin{array}{l}\text { Hospital stay } \\
\text { (days) }\end{array}$ & $13.3 \pm 15.6$ & $19.1 \pm 15.6$ & $12.1 \pm 15$ & 0.04 \\
\hline $\begin{array}{l}\text { Newly required } \\
\text { PMI }\end{array}$ & $11(7.8 \%)$ & $3(13.0 \%)$ & $8(8.5 \%)$ & 0.34 \\
\hline PVL & $14(10.0 \%)$ & $2(8.6 \%)$ & $12(10.2 \%)$ & 1.00 \\
\hline $\begin{array}{l}\text { Cerebral } \\
\text { infarction }\end{array}$ & $5(3.5 \%)$ & $1(4.3 \%)$ & $4(3.4 \%)$ & 0.82 \\
\hline $\begin{array}{l}\text { Disabling cerebral } \\
\text { infarction }\end{array}$ & $3(2.1 \%)$ & $1(4.3 \%)$ & $2(1.7 \%)$ & 0.41 \\
\hline $\begin{array}{l}\text { Acute type B } \\
\text { aortic dissection }\end{array}$ & $2(1.4 \%)$ & $1(4.3 \%)$ & $1(0.8 \%)$ & 0.30 \\
\hline Annulus rupture & $1(0.7 \%)$ & $1(4.3 \%)$ & 0 & 0.16 \\
\hline $\begin{array}{l}\text { Coronary } \\
\text { occlusion }\end{array}$ & $1(0.7 \%)$ & $1(4.3 \%)$ & 0 & 0.16 \\
\hline $\begin{array}{l}\text { Cardiac } \\
\text { tamponade }\end{array}$ & $1(0.7 \%)$ & 0 & $1(0.8 \%)$ & 1.00 \\
\hline $\begin{array}{l}\text { Esophageal } \\
\text { perforation }\end{array}$ & $1(0.7 \%)$ & 0 & $1(0.8 \%)$ & 1.00 \\
\hline
\end{tabular}

PMI: pace maker implantation, PVL: paravalvular leakage

Table 4. Predictors of mortality after transcatheter aortic valve implantation

\begin{tabular}{lllll}
\hline & Univariate analysis & Univariate analysis & Univariate analysis & Multivariate analysis \\
\hline & Hazard ratio & $(95 \%$ Confidence interval) & p value & Hazard ratio \\
Age & 0.98 & $(0.93-1.04)$ & 0.59 & \\
Female gender & 0.59 & $(0.30-1.14)$ & 0.11 &
\end{tabular}




\begin{tabular}{lllll}
\hline & Univariate analysis & Univariate analysis & Univariate analysis & Multivariate analysis \\
\hline STS risk score & 0.96 & $(0.88-1.05)$ & 0.45 & \\
EuroSCORE II & 0.92 & $(0.81-1.04)$ & 0.20 & \\
JapanSCORE & 0.95 & $(0.87-1.03)$ & 0.25 & \\
Previous cardiac surgery & 0.59 & $(0.14-2.49)$ & 0.48 & 0.60 \\
Preoperative creatinine & 1.31 & $(0.46-3.40)$ & 0.02 & 0.83 \\
Preoperative albumin & 0.37 & $(0.15-0.89)$ & 0.38 & \\
Preoperative BNP & 1.00 & $(1.00-1.01)$ & 0.01 & \\
Preoperative hemoglobin & 0.77 & $(0.63-0.95)$ & 0.14 & \\
Preoperative EF & 1.02 & $(0.98-1.05)$ & 0.11 & \\
Blood transfusion & 1.77 & $(0.89-9.49)$ & &
\end{tabular}

BNP: Brain Natriuretic Peptide, EF: Ejection fraction

\section{Supplemental Figure and Table legends}

Supplemental Figure 1. Preoperative and postoperative cardiac function evaluated by transthoracic echocardiography

The data of the nonagenarian $(\mathrm{N})$ group are presented in black, and those of the younger $(\mathrm{Y})$ group in gray. PG: pressure gradient

Supplemental Table 1. Frailty assessment of nonagenarian patients $(\mathrm{n}=15)$

$\mathrm{P}$ value was determined by comparing to preoperative state.

\% Grip strength was calculated from frailty borderline (men: $26 \mathrm{~kg}$, women: 18kg at the dominant arm).

Knee extensor strength is presented as the average of the right and left knees.

The latest assessment was performed at $4.1 \pm 2.6$ months after TAVI.

\section{Supplemental Figure 1}

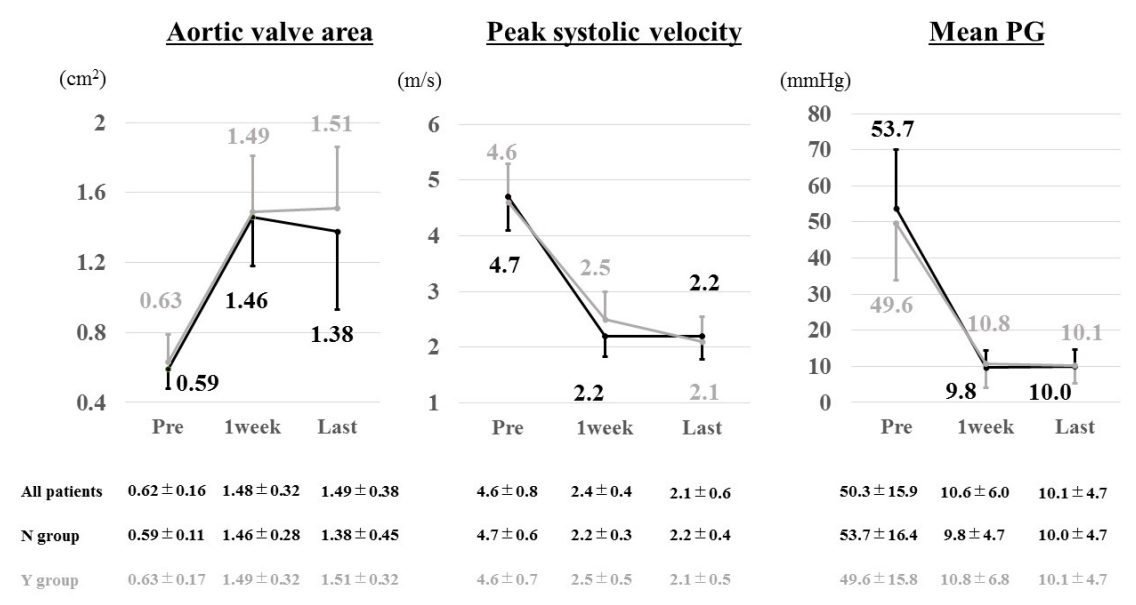

Supplemental Table 1. Frailty assessment of nonagenarian patients $(\mathrm{n}=15)$ 


\begin{tabular}{llll}
\hline & Preoperative state & At discharge ${ }^{+}$ & Latest assessment $^{+,} \mathbb{I}$ \\
\hline 5-meter walk test $(\mathrm{sec})$ & $7.2 \pm 2.4$ & $8.2 \pm 3.1(\mathrm{p}=0.24)$ & $8.7 \pm 5.2(\mathrm{p}=0.23)$ \\
\% Grip strength $(\%)^{++}$ & $74.0 \pm 19.7$ & $73.1 \pm 19.6(\mathrm{p}=0.82)$ & $74.2 \pm 22.6(\mathrm{p}=0.94)$ \\
Knee extensor strength $(\mathrm{N}){ }^{\S}$ & $145.8 \pm 63.4$ & $144.5 \pm 61.9(\mathrm{p}=0.90)$ & $127.8 \pm 59.1(\mathrm{p}=0.21)$ \\
\hline
\end{tabular}

${ }^{+} \mathrm{P}$ value was determined by comparing to preoperative state.

$++\%$ Grip strength was calculated from frailty borderline (male: $26 \mathrm{~kg}$, female: $18 \mathrm{~kg}$ at the dominant arm).

${ }^{\mathrm{SS}}$ Knee extensor strength is presented as the average of the right and left knees.

P The latest assessment was performed at 4.1+-2.6 months after TAVI.

A
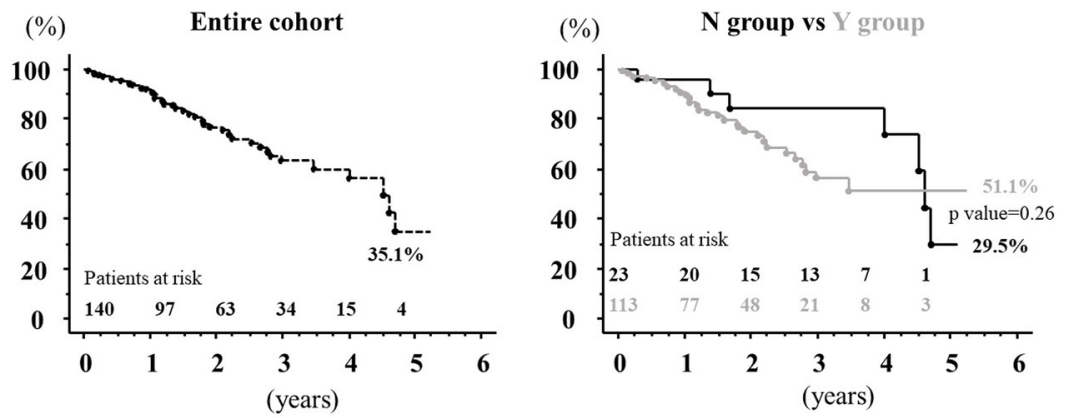

B
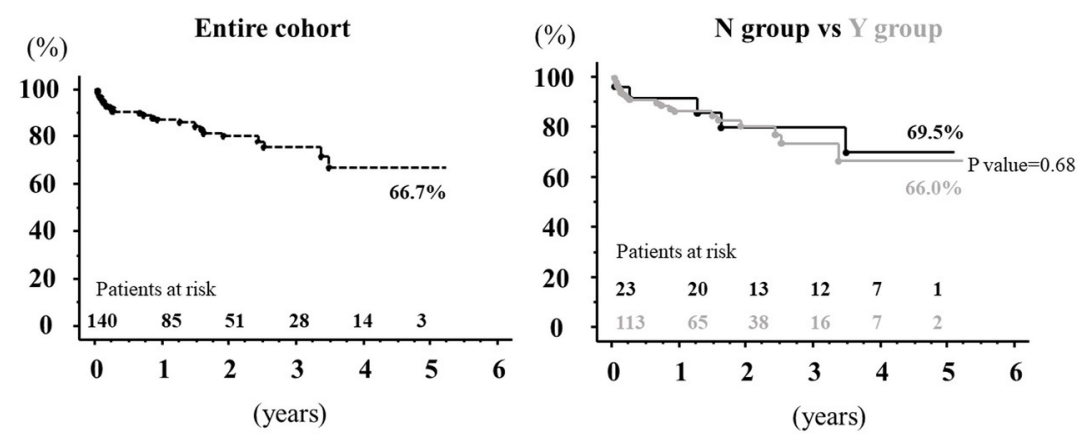

$\mathrm{C}$
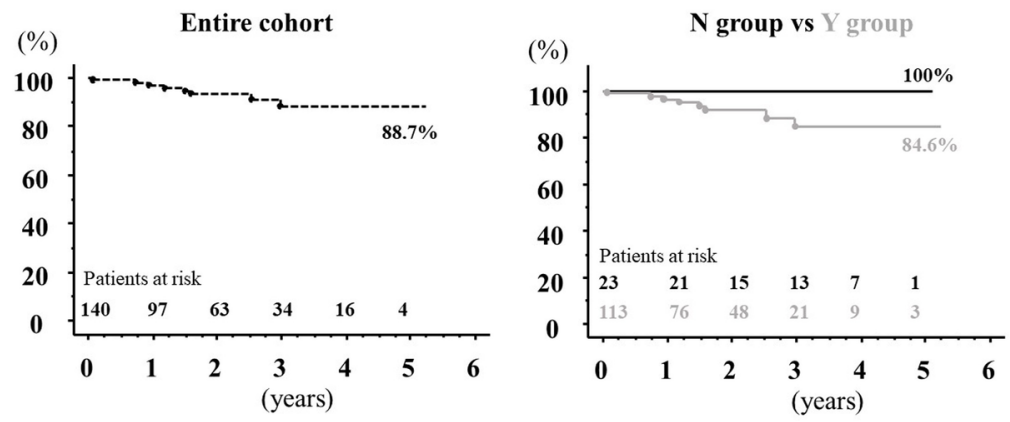